Behavior and Social Issues, 21, 135-151 (2012). C Katie Beth Miller, Emily Lund, \& Jeffrey Weatherly. Readers of this article may copy it without the copyright owner's permission, if the author and publisher are acknowledged in the copy and the copy is used for educational, not-for-profit purposes. doi: 10.5210/bsi.v21i0.4015

\title{
Applying Operant Learning to the Stay-Leave DECISION IN DOMESTIC VIOLENCE
}

\author{
Katie Beth Miller ${ }^{1}$ \\ Emily Lund \\ Jeffrey Weatherly \\ University of North Dakota
}

\begin{abstract}
Research on domestic violence has identified many factors behind an abused woman's decision to stay in, rather than leave, the relationship, including economic concerns, psychological issues, and social consequences from society and the woman's family and friends. The current article expands on Long and McNamara's (1989) and Bell and Naugle's (2005) discussions of how operant learning principles may contribute to the stay-leave decision. Human and non-human animal studies concerning the reduced effectiveness of punishment and increased effectiveness of reinforcement are discussed herein as they apply to domestic violence. Specifically, the dynamics of domestic violence increase the effectiveness of reinforcement within the relationship, decrease the effectiveness of punishment for staying in the relationship, and punish the alternative behavior of leaving the relationship. These factors combine to promote the woman staying in the relationship. Suggestions are made for modifying contingencies and a woman's behavior that could increase the likelihood that she would choose to leave a batterer.

KEYWORDS: domestic violence, behaviorism, operant learning, stay-leave decision
\end{abstract}

Researchers who study domestic violence (DV) have long attempted to parse factors influencing the stay-leave decision of women who are in abusive relationships (Rhatigan, Street, \& Axsom, 2006). To the general public, the decision to remain in or leave a violent relationship may seem an obvious one because of the negative physical and emotional consequences of DV (see, for example, Krug, Dahlberg, Mercy, Zwi, \& Lozano, 2002). However, research on the subject indicates that the stay-leave decision of women who are experiencing DV is a complex one that is influenced by situational, personal, and environ-

\footnotetext{
${ }^{1}$ Correspondence concerning this article should be addressed to Jeffrey N. Weatherly, Ph.D., Department of Psychology, University of North Dakota, Grand Forks, ND 58202-8380, Phone: (701) 7773470, Fax: (701) 777-3454, Email: jeffrey.weatherly@email.und.edu
} 
mental factors. For example, the abused woman's level of financial dependence on the perpetrator has been identified as an important factor in many stay-leave decisions (Kim \& Gray, 2008; Rhodes \& McKenzie, 1998).

Researchers have suggested that psychological factors, such as low selfesteem, negative self-beliefs brought on by emotional abuse, learned helplessness, post-traumatic stress symptoms, and self-blame, ${ }^{2}$ also influence the stay-leave decisions of women who experience DV (Rhodes \& McKenzie, 1998). Likewise, environmental and social-support factors, such as the response of law enforcement and encouragement from family members, affect the decision (Bachman \& Coker, 1995). Furthermore, women may be persuaded to stay in violence relationships due to the danger of leaving itself-battered women are most likely to be killed when they attempt to report the abuse or leave the relationship (Browne, 1987). As Rhatigan and colleagues note (2006), although there is empirical support for certain components of stay-leave decision making, such as cost-benefit analysis, there is not currently one accepted empirical model of the stay-leave decision.

Current models have differing levels of empirical support (Rhatigan et al., 2006) and may explain only certain aspects of the stay-leave decision. For example, an empirical analysis of the social learning theory of repeated victimization by Cochran, Sellers, Wiesbrook, and Palacios (2011) found that although the model had several significant findings, it explained a relatively small amount of variance in repeat victimization and attitudes towards intimate partner violence. Some subpopulations, such as women with disabilities, may have different circumstances that influence their decision-making and abuse experiences (e.g., Copel, 2006; Saxton et al., 2001), and women may endorse a variety of reasons for returning to an abusive relationship (Griffing et al., 2002). Additionally, stay-leave factors may differ for women experiencing "intimate terrorism" (i.e., more severe, repeated violence) versus situational couple violence (Johnson, 2011). Thus, a single theory is unlikely to explain stay-leave decision making perfectly or in its entirety.

However, despite the complex and multifaceted nature of stay-leave decision-making, there may be straightforward behavioral principles that help explain a woman's tendency to stay, and that fill in gaps in our understanding and conceptualization of DV. Studies conducted with both humans and nonhumans

\footnotetext{
${ }^{2}$ Although these concepts are not behavioral, one could potentially frame them as such. Specifically, conditions correlated with these concepts could be considered establishing operations (Michael, 1993) or setting events (Kantor \& Smith, 1975). Establishing operations or setting events are conditions that temporarily or relatively permanently, respectively, alter the reinforcing contingencies that control behavior. One could argue that these conditions act in these ways.
} 
have provided evidence of certain behavioral contingencies that are also applicable to DV (Long \& McNamara, 1989). Principles of operant conditioning, particularly the role of intermittent positive and negative reinforcement, the diminished effectiveness of punishment, and punishment of attempted escape behavior may potentially explain why a woman does not leave an abusive relationship (Long \& McNamara, 1989). This paper will cover these topics in the following order: 1) reinforcement for staying, particularly the increased effectiveness of positive reinforcement, the role of negative reinforcement, abusive behavior as conditioned reinforcement; 2) the reduced effectiveness of abuse as punishment; and 3) punishment for leaving, particularly response cost for leaving and abusive behavior as a punisher for leaving.

\section{Reinforcement for Staying}

\section{The Increased Effectiveness of Positive Reinforcement}

Behavior-analytic research has identified conditions that cause reinforcement to become more effective or for behavior to become more resistant to extinction. One such factor is intermittent or partial reinforcement versus continuous reinforcement. For example, Dailey, Lindner, and Amsel (1983) found that fourto-five-day-old guinea pigs demonstrated resistance to extinction (i.e., the partialreinforcement extinction effect) after having been trained to make an operant response using an intermittent schedule of reinforcement. Calef and colleagues (2007) showed that greater response rates were maintained over two stages of extinction in rats that had been exposed to intermittent reinforcement as opposed to rats that had been exposed to continuous reinforcement. Such outcomes have been reported for decades (e.g., Ferster \& Skinner, 1957) and have been shown to be highly reliable in both humans (Lerman, Iwata, Shore, \& Kahng, 1996) and non-humans.

In terms of DV, one characteristic of these relationships is the unpredictability of the abuser's behavior (Campbell \& Lewandowski, 1997) and thus, the intermittent nature of reinforcement provided in those relationships. Notably, Walker (1979) proposed a cycle of violence in which the abuser cycles through phases of tension building, abusive behavior, and reconciliatory or apologetic behavior and promises to change. This cycle, particularly the "honeymoon phase," has been the subject of some controversy (e.g., Copel, 2006; Rhatigan et al., 2006). When constructing a cycle of abuse with women with physical disabilities, Copel and colleagues (2006) found that these women did not experience a honeymoon phase and instead only experienced a separation from the perpetrator or a "cooling off period" of little interaction before the cycle re- 
entered the "tension" phase. It may be that the cycle of violence differs for women with disabilities because they are often physically dependent on the perpetrator and therefore, face significant additional barriers to leaving (e.g., Saxton et al., 2001). Similarly, in their discussion of empirical support for theories of stay-leave decision-making, Rhatigan and colleagues (2006) noted that portions of Walker's (1979) cycle may only apply to subsets of abused women, particularly those who experience more extreme abuse or intimate terrorism, as did Johnson (2011).

However, some women do report experiencing reconciliation, remorse, or promises of change from their perpetrators following abuse. Griffing and colleagues (2002) interviewed 90 survivors of DV who were staying at a residential shelter. Of the sixty women who reported having left and then returned to an abusive relationship in the past, $90 \%$ reported doing so at least in part because the batter expressed remorse for his actions, providing support for the idea of a "honeymoon" or reconciliation phase following abuse and separation that is experienced by at least some women in abusive relationships. Some psychologists have argued that this erratic behavior pattern by the abuser has been reinforced because it helps to maintain power and control in the relationship (Walker, 1979).

From a behavioral perspective, given what studies have demonstrated regarding the effects of partial reinforcement on the maintenance of behavior (Calef et al., 2007; Dailey et al., 1983), this erratic behavior by the perpetrator serves as an intermittent schedule of reinforcement. As such, the abused partner's behavior pattern becomes resistant to extinction, with the operant in this case being responding within the relationship. In non-technical terms, the abusive partner's intermittent moments in which he treats the abused partner with affection and kindness make it more likely that she will stay in the relationship.

Another situation that has been identified as having the potential to increase the effects of positive reinforcement is deprivation of the reinforcer. Rosenblum and Harlow (1973) found that affection-deprived rhesus monkeys spent more time clinging to a surrogate mother made of cloth despite being presented with an intermittent aversive blast of air when having contact with surrogate. In fact, the authors proposed that the aversive stimulus actually increased the monkeys' responsiveness (Rosenblum \& Harlow, 1973). Rosenblum and Harlow suggested that because the monkeys had been deprived of affection, their unmet desire for affection likely made them more willing to endure punishment. In behavioral terms, these results suggest that deprivation of the reinforcer was potentially serving as an establishing operation (Michael, 1993) that altered both the reinforcement and punishment contingencies in the DV relationship. 
The Rosenblum and Harlow (1973) study would appear relevant to DV situations because it could be argued that women in these relationships go through periods in which they are deprived of primary reinforcement (e.g., attention, affection). This deprivation makes these outcomes more effective reinforcers when they do indeed occur. If the aversive events, such as abuse, exacerbate this effect, then these reinforcers would be expected to strongly maintain the woman's behavior of staying in the relationship.

This situation may be especially acute right after a battering incident. According to Walker's (1979) "cycle of violence" theory, the abuser withholds affection from the abused partner during the "tension-building phase" that precedes the physical battering incident. After the physical incident, the abuser then acts reconciliatory and contrite, which Walker refers to as the "honeymoon phase." He may tell his abused partner that he is sorry, that he loves her, and that the abuse will stop (Walker, 1979). He may also shower her with gifts and affection that had been withheld during the tension-building phase (Walker, 1979). Although one might surmise that the abuse would serve as a punisher for staying in the relationship, the staying behavior is also positively reinforced through affection and promises that occur after the abuse. Because the abused partner has been previously deprived of these reinforcers, her behavior is especially susceptible to being controlled by them.

There is evidence that affection for the abusive partner influences stay-leave decision-making. For example, in Griffing and colleagues' (2002) study, slightly over $70 \%$ of women cited affection for their abusive partner as a motivation for returning to the relationship following their separation. Additionally, Rhatigan and colleagues (2006) discuss the strong empirical support for the influence of positive relationship factors, including affection for and intimacy with their partner, in a women's decision to stay in or leave any relationship, including abusive ones. Thus, it appears that affection from a partner has the potential to be a strong reinforcer for staying for many—although not all—women.

\section{The Role of Negative Reinforcement}

As briefly noted above, negative reinforcement may also play a role in why women stay in abusive relationships. In her cycle of violence theory, Walker (1979) postulated that the phase before the abusive incident is the "tensionbuilding phase." During this phase, the abuser is irritable, verbally abusive, and critical towards the abused partner. However, after the physical battering incident, the abuser stops acting this way. According to Walker (1979), the abuse is also often preceded by anticipation of the abuse by the abused woman, who does not 
know what will provoke the abuser's violent behavior, which causes her to live in perpetual fear and anxiety of a physical incident (Walker, 1979). After the battering incident, the aversive stimuli of tension, verbal abuse, sullenness of the abuser, and anticipation of the abuse are no longer present or at least reduced in severity. This pattern of tension building and "cooling off" periods was further supported by Copel's (2006) work with women with physical disabilities. Although these women did not report a honeymoon or positive reinforcement phase following abuse, they did report a period of negative reinforcement in which their abusive partner left or avoided interaction. Copel notes that several women reported a "feeling of peacefulness" (p. 120) during this period, and that some were also reinforced by the feeling that perhaps that abuser "would go and disappear" or even die during this period of separation, thus ending both the phases of tension building and abuse (p. 120).

Thus, there may be several aspects of negative reinforcement operating in this situation. As stated above, staying in the relationship after an abusive episode may be reinforced by the removal of the immediate threat of additional violence. Staying after the battering stage may also be due to matching, as the individual in the relationship returns to the staying behavior that was occurring before the abuse. Furthermore, the victim's response to the abuse may be negatively reinforced. It may also be reinforced by the removal of any anxiety or anticipation that is associated with potentially impending physical violence, which Long and McNamara (1989) suggested might be more aversive than the violence itself. This interpretation would be consistent with basic research that has demonstrated that negative reinforcement can maintain behavior even in situations in which escape from the aversive stimuli is not possible (e.g., Herrnstein \& Hineline, 1966). Therefore, her decision to stay is negatively reinforced, which results in the increase in relationship-related behaviors that might include telling the abuser that she loves him, performing chores or tasks that the abuser demands her to do, hanging up on calls from domestic violence agencies or other concerned parties, breaking off contact with people that the abuser does not want her to see, lying to others about the origins of her injuries, and telling other people that she is happy in the relationship.

\section{Abusive Behavior as a Conditioned Reinforcer}

The roles of intermittent reinforcement, deprivation, response cost, and negative reinforcement contingencies are relatively straightforward applications of basic behavioral principles to a battered woman's stay-leave decision. A perhaps less straightforward application would involve viewing the abuse in a DV 
relationship as a conditioned reinforcer. This idea is not new; Long and McNamara (1989) discussed the role of abuse as a reinforcer as it relates to domestic violence. Although abuse is generally assumed to be aversive and should therefore act as punisher, Long and McNamara argued that the abuse can also act as a reinforcer under certain circumstances. They called such circumstances "paradoxical" to the typical view of abuse as an obvious aversive-and therefore, purely punishing-stimulus. They proposed that the abuse acquired reinforcing properties because it is paired with a subsequent reinforcer (i.e., the attention and affection that typically occurs after an abusive episode). The abuse thus acquires discriminant properties (Long \& McNamara, 1989) that causes it to act as a reinforcer in the future. Notably, even in populations in which abuse is not followed by positive reinforcement, such as women with physical disabilities, abuse is usually followed by the negative reinforcement of a "cooling off" or separation period (Copel, 2006).

This notion has support from the basic literature. For instance, Holz and Azrin (1961) found that pigeons had a higher rate of responding in a punishment condition after the punisher had been paired with a reinforcer and was discriminated from no-punishment/no-reinforcement in a previous condition. Similar effects have also been observed with human participants. For instance, Ayllon and Azrin (1966) demonstrated that mental hospital inpatients would respond to get a previously punishing noise after the noise had been paired with a reinforcer and was discriminated from a no-reinforcement/no-punishment condition (Ayllon \& Azrin, 1966). The participants displayed high response rates even when the behavior produced only the noise but not the original reinforcer, indicating the strength of this effect (Ayllon \& Azrin, 1966).

The question, from a behavior-analytic perspective, would be whether the abuse is serving as a reinforcer or whether it is serving as a discriminative stimulus for the availability of upcoming reinforcement. If it is serving as a reinforcer, then the woman may engage in behavior to produce this consequence. Although it might be counterintuitive and socially controversial, such an idea has been proposed before (Walker, 1979), albeit in non-behavioral terms. The alternative would be that the abuse signals a period in which the abuser attempts to reconcile with the victim by acting loving and apologetic, a period which can be high in reinforcement. While the distinction between these possibilities is theoretically interesting, parsing them likely serves little practical purpose ${ }^{3}$

\footnotetext{
${ }^{3}$ It should also be noted that a third potential interpretation could be added to this discussion. Basic research (e.g., Kelleher \& Morse, 1968; Kelleher, Riddle, \& Cook, 1963) has demonstrated that behavior can potentially be maintained by intuitively aversive consequences, such as electric shock. It is theoretically possible that a similar phenomenon occurs in DV relationships.
} 
because, regardless of which is correct, extinguishing the reinforcing or discriminative properties of the abuse would occur in the same fashion. Specifically, the abuse would need to stop being paired with reinforcement or its availability. Unfortunately, doing so would require removing the woman from the situation subsequent to the abuse, which is unlikely because (a) women tend not to leave the abusive relationship and (b) the woman would be foregoing what is likely the most reinforcing period in the relationship.

\section{The Reduced Effectiveness of Punishment}

In addition to the punisher also serving as a reinforcer or as a discriminative stimulus for reinforcement, the punishing effects of abuse in a DV relationship may also be lessened because abuse in these relationships typically violates all of the rules of an effective punishment contingency. For instance, punishment is known to be effective if it is intense and begins at its maximum intensity, both of which have been long supported by basic research. Karsh (1962) found that mild levels of shock intensity did not result in suppression of behavior. The running speed of rats in a maze decreased as a function of shock intensity, with the highest level of shock producing the lowest running speed. Moderate levels of shock caused the animals' performance to decrease and remain at a consistently lowered speed (Karsh, 1962). Rats given mild shock showed very little decrease in speed (Karsh, 1962).

In terms of starting at its maximum intensity, basic research has demonstrated that animals with a prior history of punishment have been found to continue their behavior even when punishment is continued and made more intense and frequent (Banks, 1976). Cohen (1968) found that rats that had received mild shocks demonstrated less decrease in behavior after being delivered severe shock than rats that had not previously received mild shock. At a theoretical level, one possible explanation for these findings is that organisms habituate to punishers and, by presenting them in increasing intensities, the organism has an extended chance to experience and therefore to habituate to the maximum intensity, which ultimately lessens their effectiveness (Banks, 1976).

Survivors of DV often discuss how the abuse did not suddenly begin overnight (Kubany \& Ralston, 2008). Usually, when the woman meets the abuser, he comes across as charming, gentlemanly, and doting (Kubany \& Ralston, 2008), and the abuse begins with gradual establishment of isolation and control (Short et al., 2000). The physical abuse will also often begin with "milder" forms of physical violence and escalate in severity (Walker, 1979). Therefore, the punishment effect of the abuse may be less effective because it was not presented initially at a high intensity and its intensity increases over time. Furthermore, 
often many victims of DV are also victims or witnesses of DV as children, so they may have had exposure to abuse, and had the opportunity to habituate to it, before ever meeting an abusive partner (O'Keefe \& Treister, 1998). Cochran and colleagues (2011) found that people who had experienced victimization by a previous partner were significantly more likely to adopt positive stances toward partner abuse compared to those who had not experienced previous abuse by a partner. This finding supports the idea that previous experience with abusive partners may actually prime people for future abusive relationships.

Next, research also has demonstrated that in order for punishment to be most effective, it should be immediate and consistent. For example, Cohen (1968) found that higher shock intensity was necessary to suppress behavior in animals that were given a delay between the behavior and the delivery of the punisher. Kinler and Banks (1969) demonstrated that intermittent punishment of a behavior in rats increased persistence against later continuous punishment.

These principles are also violated in DV situations. Typically, physical abuse is not linked to a unique event that sets it off. In other words, abuse is often independent of the woman's behavior and thus does not immediately occur after a certain behavior (e.g., Campbell \& Lewandowski, 1997; Walker, 1979). Basic research has demonstrated that non-contingent punishment does not suppress behavior as would be expected with response-contingent punishment (e.g., Frankel, 1975). Furthermore, research on non-contingent aversives indicates that repeated punishment can be generalized and lead to non-action in other situations because the punisher is seemingly non-contingent with a given behavior (Seligman \& Maier, 1967). As mentioned earlier, the abusive behavior is often intermittent and the abused partner cannot predict when she will be physically battered (Campbell \& Lewandowski, 1997). Because the punishing stimulus is not consistently linked to specific antecedent or antecedents, a clear antecedentbehavior-consequence relationship cannot be established with abuse, potentially reducing the ability of the abuse to serve as a punisher.

Two findings already discussed in regards to effectiveness of reinforcement also relate to effectiveness of punishment. As was discussed earlier, deprivation of a reinforcer can increase the effectiveness of the reinforcer. This deprivation can also increase the persistence of operant behavior in the presence of potential punishers (Rosenblum \& Harlow, 1973). An organism is likely to endure higher levels of punishment if it is deprived of the reinforcer (Rosenblum \& Harlow, 1973). In other words, a powerful enough reinforcer may outweigh the effects of even a potent punisher in determining future behavior. The cost of the alternative behavior can also decrease effectiveness of the punishment if its cost outweighs the benefit (e.g., Pietras, Brandt, \& Searcy, 2010; Pietras \& Hackenberg, 2005). 
MILLER, LUND, \& WEATHERLY

\section{Punishment for Leaving}

\section{Response Cost}

Another situational factor that helps prevent leaving is the cost of leaving. Response cost - that is, aspects of behavior that bring about consequences that may serve as negative or positive punishers - has been shown to influence human behavior (e.g., Pietras, Brandt, \& Searcy, 2010). For instance, studies have demonstrated that the rate of an alternative operant response will decrease if it requires too much effort relative to the original response, even if the alternative response is reinforced and the original response is punished (Pietras \& Hackenberg, 2005). In this instance, the cost associated with leaving combines with the punishment for leaving delivered by the abuser to decrease the probability that the woman will, in fact, leave the relationship.

The response cost of leaving a DV relationship can be quite high. That is, there are many social and financial factors that impose a response cost for leaving. Costs would include behaviors such as answering calls from domestic violence agencies, visiting agencies, calling or making contact with friends or family that can help with escape arrangements, creating an escape plan and a place to stay, contacting legal authorities to find out about divorce or custody proceedings, and leaving behind one's home and belongings. These costs could also be emotional such as experiencing the end of the relationship and fear of pursuit by the abuser. One of the largest may be the woman's financial dependence on the perpetrator and her resulting lack of financial resources if she were to leave the abusive relationship. Indeed, some research indicates that the amount of economic resources available to a woman is in fact the best predictor of whether she will stay in or leave the relationship (Barnett, 2001). According to Walker (1994), $27 \%$ of abused women reported that their abuser did not allow them access to any money, and 51\% reported having no access to charge accounts. Barnett (2001) also identified the availability of social support and community resources as an important factor in whether or not a woman leaves the relationship. The absence of financial and/or social resources means that the abused woman may need to go to excessive lengths to get these things if making the alternative response (i.e., leaving the relationship). The research on response cost supports the notion that, under these conditions, making the original response (i.e., staying in the relationship) would be expected. Isolation by the abuser prevents access to social reinforcers.

A similar argument can be made for another major factor for staying in an abusive relationship: children. Concern for her children may prompt an abused 
woman to leave an abusive relationship, but it can also be a reason to stay. According to Barnett (2001), a woman leaving the relationship may prompt an investigation from Child Protective Services because often she is blamed for the children having been witnesses to violence or victims of violence from the abuser. The abuser may also threaten to take custody of the children, kidnap them, or hurt them (Rhodes \& McKenzie, 1998), which may not only act as a punisher for leaving the relationship, but also increases the response cost of leaving.

Researchers outside behavioral psychology have alluded to this issue of response cost, but they have not done so within the context of a behavior-analytic framework. For instance, Barnett (2001) describes an abusive relationship as having "a combination of costs and benefits." On the one hand, there are the benefits of "love and economic support" (p. 14). On the other hand, there are also costs of "fear and degradation" (p. 14). In other words, leaving a relationship bears high costs and requires high effort for the abused woman. As behavioral studies have demonstrated with both humans and non-humans, the high cost of the leaving response results in its suppression. It should also be noted that this behavior may be rule-governed, as many abused women know that leaving will difficult even if they have not attempted it before. Rule-governed behavior refers to behaviors that are modified by verbal instruction (Baron \& Galizo, 1983).

\section{Conclusions}

As mentioned earlier, the costs of the alternative behavior to staying in the relationship (i.e., leaving the relationship) are extremely high for women in domestic abuse situations (Rhodes \& McKenzie, 1998). Notwithstanding the reinforcement for staying, women experiencing DV often face a high likelihood of diminished economic viability, threats to the safety of themselves and their children, and may also experience pressure from their friends, family, and religion to stay in the relationship (Barnett, 2001). Furthermore, when a woman does choose to leave, her behavior is often punished in the form of those negative economic consequences and increased abusive behavior (Long \& McNamara, 1989, Copel, 2006). Aside from economic struggles and losing the stability of a long-term home and relationship, it is also an extremely dangerous time for her as the abuser will often pursue her, threaten her, and at the very least attempt to make her life more difficult (Browne, 1987). Given the reinforcers that may be available in a relationship, albeit intermittently, the cost of the alternative behavior, the reduced effectiveness of the abuse punishing the staying behavior, and the punishment of the leaving behavior, it is not surprising that many women remain in the relationship. Cochran and colleagues (2011) found that people who anticipated more positive consequences (i.e., reinforcement) from abuse were 
more likely to adopt positive conceptualizations of abuse, and Rhatigan and colleagues (2006) discuss the relatively strong empirical support for cost-benefit analyses (e.g., potential reinforcement for staying versus potential punishment for leaving) in the decision to leave or maintain a relationship).

In conclusion, the decision to leave an abusive relationship is highly complex. Numerous factors play a role in stay-leave decision-making (Rhodes \& McKenzie, 1998; Kim \& Gray, 2008), and many of these factors can be explained through behavioral principles (Bell \& Naugle, 2005; Long \& McNamara, 1989; Present paper). When considering the empirically-demonstrated characteristics of reinforcement and punishment, it appears that the decision to stay in DV situations may be behaviorally driven. The staying behavior may persist due to a combination of intermittent reinforcement within the abusive relationship, relative deprivation of the reinforcers available within the relationship, a high response cost for leaving the relationship, the possibility that the abuse comes to have reinforcing or discriminative properties, and a decrease in the ability of the abuse to serve as a punisher.

\section{Implications for Intervention}

A behavioral model of stay-leave decision-making, as detailed above, naturally has implications for intervention. Because many of the behavioral principles that influence stay-leave decision-making are rooted in the perpetrator's behavior and overall cycle of violence, they may be out of the reach of clinicians who work with victims of DV. Therefore, behavioral interventions may focus more on changing the conditions that influence the victim's stay-leave behavior through altering contingencies and motivating operations.

For example, Bell and Naugle (2005) conceptualize motivational interviewing through a behavioral or applied-behavioral lens. In their model, motivational interviewing works to increase motivative operations for leaving the violent relationship. In other words, it increases the appeal of the reinforcers associated with leaving (i.e., it attempts to set up establishing operations for leaving the relationship), thereby making leaving a more desirable (i.e., more highly reinforced) choice, which in turn should increase the likelihood of it occurring. Likewise, another technique that may be helpful is discovering or introducing new reinforcers for leaving, such as social reinforcement for leaving that may be offered by DV organizations or therapists. Support groups may also be useful behaviorally because they provide social reinforcement, shifts in relational responding, and changes in the contingencies that make it less likely for women to leave abusive relationships. By increasing the number and/or power of the reinforcers for leaving, it would decrease the relative difference between the 
response costs and the rewards of leaving the relationship, thus resulting in leaving behavior becoming more probable. Research indicates that using a motivational interviewing approach, which works to resolve ambivalence towards change and increase dissonance between desired goals and current behaviors, may be effective at reducing aggressive behaviors and acceptance of aggressive behavior in physically aggressive dating couples (Woodin \& O'Leary, 2010). However, whether or not it serves to create the establishing operations described by Bell and Naugle (2005) has yet to be firmly established.

Similarly, interventions could work to decrease the response cost directly through reducing the potency of the punishers associated with leaving. For example, the victim could be provided with resources through DV or other social services organizations, thereby at least temporarily reducing the financial and other resource costs of leaving the abuser. In other words, this approach may reduce the likelihood of a financial crisis serving to punish leaving the relationship, and thus increasing the likelihood of leaving. As another example, the potential response cost of harm (or fear of harm) to the victim's children may be reduced through creating a specific plan to increase the children's safety, especially during and after the act of leaving. This step would reduce the level of anxiety the woman might experience regarding the children's well-being if she were to leave the relationship, thereby potentially reducing or removing the negative reinforcement contingency for staying in the relationship.

Domestic violence shelters already offer shelter and advocacy, and research indicates that these services are helpful for women (Bowker \& Maurer, 1986; Donato \& Bowker, 1984). Studies also indicate that women who receive advocacy services from DV agencies report higher levels of support and resources than women who do not receive them (Sullivan, Campbell, Angelique, Eby, \& Davidson, 1994; Sullivan, Tan, Basta, Rumptz,\& Davidson, 1992). If women have greater resources after leaving, they will likely experience fewer punishing contingencies. Myers (1995) also agrees that providing more access to resources, such as those provided by domestic violence agencies, would increase the likelihood of a woman leaving an abusive relationship.

Previous research (e.g., Hughes et al., 2010) has examined action planninga form of behavioral activation combined with positive social reinforcement - in the context of safety planning for interpersonal violence. Action planning encourages people to set operationally defined and achievable goals to increase their safety or well-being and is one potential strategy for reducing the response cost of leaving. For example, an action plan for a woman who has identified a lack of financial support as a response cost for leaving might involve a series of small, concrete steps that she could take to secure financial assistance or resources 
upon leaving the violent relationship. Such plans might be effective because they work as behavioral contracts, as well as provide relational responding and changes in rule governance.

Because action planning often involves breaking down a desired behavior change into multiple, gradual steps, it can also be conceptualized as a way of shaping behavior that either reduces the response cost of leaving or directly involves leaving the violent relationship. Due to the high potential response costs of leaving a violent relationship (Rhodes \& McKenzie, 1998) and the fact that many survivors of DV have become well attuned to the cycle of abuse over time (Kubany \& Ralston, 2008), gradual shaping may be necessary to achieve behavior change. For example, a survivor of DV may have become so habituated to isolation by the abuser that the lack of social support is no longer a powerful aversive stimulus (see Kubany \& Ralston, 2008), thereby reducing the potency of the deprivation condition and the motivation of the woman to seek social support on her own. Action planning can shape social-support-seeking behavior gradually by pairing the behavioral approximations with either tangible or intangible reinforcement from a therapist or peer group until the social support itself is a strong enough reinforcer to offset some of the response cost associated with leaving.

Perhaps a useful step in being able to determine what type of intervention would be helpful in getting any specific DV victim to leave the relationship would be to develop a functional assessment tool that would determine which of the above contingencies might be at work in the woman's specific situation. Such tools could be brief and quite informative, as it is likely that each individual woman's relationship will not necessarily contain all of the possible behavioral aspects listed in this paper. A functional assessment tool would help therapists target specific plans for changing the environment that would increase the probability that the woman would permanently leave the abusive relationship.

In the absence of such a tool, clinicians who work with clients who are in DV relationships should thoroughly investigate the reinforcers and punishers that influence each client's stay-leave decision-making and their relative strength. Doing so will allow the clinician to employ client-specific behavior-modification strategies like those described above to increase the potency of potential reinforcers for leaving, reduce the response cost associated with leaving, and reduce negative reinforcement of staying. Because staying in the DV relationship has likely been reinforced over a long period of time (Kubany \& Ralston, 2008), and the response cost and increased probability of further abuse for leaving are often high (Barnett, 2001; Rhodes \& McKenzie, 1998), behavioral change may have to be gradual. A successful treatment would also have to potentially address 


\section{OPERANT LEARNING AND THE STAY-LEAVE DECISION}

the behavioral momentum (see Nevin \& Shahan, 2011) for continuing the present, known, highly-practiced behavior of staying in the relationship. However, behavioral interventions have the advantage of directly and explicitly addressing the factors that reinforce staying in the relationship or punish leaving the relationship. This advantage may lead to direct, targeted interventions that are specific to the client's individual situation, potentially increasing the potency of the interventions and in turn decreasing the time that the abused partner remains in the violent relationship. Research may also want to examine the stay-leave decision within a delay-discounting paradigm (see Madden \& Bickel, 2010, for a review) to determine if rates of discounting are predictive of behavior in DV relationships.

\section{References}

Ayllon, T. T., \& Azrin, N. H. (1966). Punishment as a discriminative stimulus and conditioned reinforcer with humans. Journal of the Experimental Analysis of Behavior, 9, 411-419.

Bachman, R., \& Coker, A. L. (1995). Police involvement in domestic violence: The interactive effects of victim injury, offender's history of violence, and race. Violence and Victims, 10, 91-106.

Banks, R. K. (1976). Attenuation of the intermittent punishment effect: The effect of interpolated punishment and nonreward trials. Animal Learning \& Behavior, 4, 118-120.

Barnett, O. W. (2001). Why battered women do not leave, part 2: External inhibiting factorssocial support and internal inhibiting factors. Trauma, Violence, \& Abuse, 2, 3-35.

Baron, A., \& Galizo, M. (1983). Instructional control of human operant behavior. The Psychological Record, 33, 495-520.

Bell, K. M., \& Naugle, A. E. (2005). Understanding stay/leave decisions in violent relationships: A behavior analytic approach. Behavior and Social Issues, 14, 21-45.

Bowker, L. H., \& Maurer, L. (1986). The effectiveness of counseling services utilized by battered women. Women \& Therapy, 5, 65-82.

Browne, A. (1987). When battered women kill. New York: Free Press.

Calef, R. S., Choban, M. C., Glenney, K. R., Calef, R. A., Schmitt, E., Hinte, S., \& ... Richards, S. D. (2007). Perseveration of the partial reinforcement effect in extinction with rats over two phases of extinction and two stages of continuous reinforcement. Psychological Reports, 100, 101-107.

Campbell, J. C., \& Lewandowski, L. A. (1997). Mental and physical health effects of intimate partner violence on women and children. Psychiatric Clinics of North America, 20, 353-374.

Cochran, J. K., Sellers, C. S., Wiesbrock, V., \& Palacios, W. R. (2011). Repetitive intimate partner victimization: An exploratory application of social learning theory. Deviant Behavior, 32, 790-817.

Cohen, P. S. (1968). Punishment: The interactive effects of delay and intensity of shock. Journal of the Experimental Analysis of Behavior, 11, 789-799.

Copel, L. C. (2006). Partner abuse in physically disabled women: A proposed model for understanding intimate partner violence. Perspectives in Psychiatric Care, 42(2), 114-129.

Dailey, W. A., Lindner, M., \& Amsel, A. (1983). The partial-reinforcement extinction effect in 45-day-old guinea pigs. Animal Learning \& Behavior, 11, 337-340. 


\section{MILLER, LUND, \& WEATHERLY}

Donato, K. M., \& Bowker, L. H. (1984). Understanding the help-seeking behavior of battered women: A comparison of traditional service agencies and women's groups. International Journal of Women's Studies, 7, 99-109.

Ferster, C. B., \& Skinner, B. F. (1957). Schedules of Reinforcement. Englewood Cliffs, NJ: Prentice Hall.

Frankel, F. D. (1975). The role of the response-punishment contingency in the suppression of a positively-reinforced operant. Learning and Motivation, 6, 385-403.

Griffing, S., Ragin, D. F., Sage, R. E., Madry, L., Bingham, L. E., \& Primm, B. J. (2002). Domestic violence survivors' self-identified reasons for returning to abusive relationships. Journal of Interpersonal Violence, 17, 306-319.

Herrnstein, R. J., \& Hineline, P. N. (1966). Negative reinforcement as shock-frequency reduction. Journal of the Experimental Analysis of Behavior, 9, 421-430.

Holz, W. C., \& Azrin, N. H. (1961). Discriminative properties of punishment. Journal of the Experimental Analysis of Behavior, 4, 225-232.

Hughes, R. B., Robinson-Whelen, S., Pepper, A., Gabrielli, J., Lund, E., M., Legerski, J., \& Schwartz, M. (2010). Development of a safety awareness program for women with diverse disabilities. Rehabilitation Psychology, 55, 263-271.

Kantor, J. R. \& Smith, N. W. (1975). The science of psychology: An interbehavioral survey. Principia Press, Inc: Chicago, IL.

Karsh, E. B. (1962). Effects of number of rewarded trials and intensity of punishment on running speed. Journal of Comparative and Physiological Psychology, 55, 44-51.

Kelleher, R. T., \& Morse, W. H. (1968). Schedules using noxious stimuli: III. Responding maintained with response-produced electric shocks. Journal of the Experimental Analysis of Behavior, 11, 819-838.

Kelleher, R. T., Riddle, W. C., \& Cook, L. (1963). Persistent behavior maintained by unavoidable shocks. Journal of the Experimental Analysis of Behavior, 6, 507-517.

Kim, J., \& Gray, K. A. (2008). Leave or stay?: Battered women's decision after intimate partner violence. Journal of Interpersonal Violence, 23, 1465-1482.

Kinler, R. M., \& Banks, R. K. (1969). The intermittent punishment effect: A replication with improved controls. Psychonomic Science, 15, 267.

Krug, E.G., Dahlberg, L., Mercy, JA., Zwi, A.B., \& Lozano, R. (2002). World report on violence and health. Geneva: World Health Organization.

Kubany, E. S., \& Ralston, T. C. (2008). Treating PTSD in battered women: A step-by-step manual for therapists and counselors. Oakland, CA US: New Harbinger Publications.

Lerman, D. C., Iwata, B. A., Shore, B. A., \& Kahng, S. W. (1996). Responding maintained by intermittent reinforcement: Implications for the use of extinction with problem behavior in clinical settings. Journal of Applied Behavior Analysis, 29, 153-171.

Long, G. M., \& McNamara, J. (1989). Paradoxical punishment as it relates to the battered woman syndrome. Behavior Modification, 13, 192-205.

Johnson, M. P. (2011). Gender and types of intimate partner violence: A response to an antifeminist literature review. Aggression and Violent Behavior, 16, 289-296.

Madden, G. J., \& Bickel, W. K. (2010). Impulsivity: The behavioral and neurological science of discounting. Washington, D.C.: American Psychological Association.

Michael, J. (1993). Establishing operations. The Behavior Analyst, 16, 191-206.

Myers, D. L. (1995). Eliminating the battering of women by men: Some conditions for behavior analysis. Journal Of Applied Behavior Analysis, 28, 493-507. 


\section{OPERANT LEARNING AND THE STAY-LEAVE DECISION}

Nevin, J. A., \& Shahan, T. A. (2011). Behavioral momentum theory: Equations and applications. Journal of Applied Behavior Analysis, 44, 877-895.

O'Keefe, M., \& Treister, L. (1998). Victims of dating violence among high school students: Are the predictors different for males and females? Violence Against Women, 4, 195-223.

Pietras, C. J., \& Hackenberg, T. D. (2005). Response-cost punishment via token loss with pigeons. Behavioural Processes, 69, 343-356.

Pietras, C. J., Brandt, A. E., \& Searcy, G. D. (2010). Human responding on random-interval

schedules of response-cost punishment: The role of reduced reinforcement density. Journal of the Experimental Analysis of Behavior, 93, 5-26.

Rhatigan, D. L., Street, A. E., \& Axsom, D. K. (2006). A critical review of theories to explain

violent relationship termination: Implications for research and intervention, Clinical Psychology Review, 26, 321-345.

Rhodes, N. R., \& McKenzie, E. (1998). Why do battered women stay?: Three decades of research. Aggression and Violent Behavior, 3, 391-406.

Rosenblum, L. A., \& Harlow, H. F. (1963). Approach-avoidance conflict in the mother-surrogate situation. Psychological Reports, 12, 83-85.

Saxton, M., Curry, M. A., Powers, L. E., Maley, S., Eckels, K., \& Gross, J. (2001). "Bring my scooter so I can leave you": A study of disabled women handling abuse by personal assistance providers. Violence Against Women, 7, 393-417.

Seligman, M.E.P.\& Maier, S.F. (1967). Failure to escape traumatic shock. Journal of Experimental Psychology, 74, 1-9.

Short, L. M., McMahon, P. M., Davis Chervin, D., Shelley, G. A., Lezin, N., Sloop, K., \& Dawkins, N. (2000). Survivors' identification of protective factors and early warning signs for intimate partner violence. Violence Against Women, 6, 272-285.

Sullivan, C. M., Campbell, R., Angelique, H., Eby, K. K., \& Davidson,W. S. (1994). An advocacy intervention program for women with abusive partners: Six-month follow-up. American Journal of Community Psychology, 22, 101-122.

Sullivan, C. M.,Tan, C., Basta, J., Rumptz, M., \& Davidson,W. S. (1992). An advocacy intervention project for women with abusive partners: Initial evaluation. American Journal of Community Psychology, 20, 309-332.

Walker, L. E. (1979). The battered woman. New York: Harper \& Row.

Woodin, E. M., \& O’Leary, K. (2010). A brief motivational intervention for physically aggressive dating couples. Prevention Science, 11, 371-383 